\title{
What is genetic discrimination, and when and how can it be prevented?
}

\author{
Mark A. Rothstein, JD, and Mary R. Anderlik, JD, PhD
}

The public policy debate concerning the desirability and scope of legislation prohibiting genetic discrimination has become increasingly volatile. Last year, a provocative opinion piece urging citizens to "gather courage to discriminate genetically" was widely syndicated ${ }^{1}$; another commentator suggested that genetic discrimination is "both rational and inevitable." 2 On the other hand, some prominent genetic scientists and legislators, as well as disease support groups, continue to make passage of laws with strong protections for affected individuals one of their top policy priorities. ${ }^{3,4}$ Genetic researchers and clinicians need to recognize the unarticulated assumptions about discrimination that shape the debate and understand the underlying tensions between differing accounts of justice and fairness. In this article, we explore some of the nuances of the term discrimination and some of the sources of disagreement, before asking when and how genetic discrimination can be prevented.

\section{What is discrimination?}

The two most common uses of the term discrimination differ dramatically in the degree of disapproval they connote. On the one hand, the term discrimination may be used to indicate a type of distinction that invariably is or should be socially unacceptable. We refer to this as the civil rights definition. For example, the Council for Responsible Genetics position paper on genetic discrimination does not define the term discrimination, but the negative connotation is clear from its use. Discrimination is linked to evaluating people based on "questionable stereotypes" rather than their individual merits and abilities, invading people's privacy, the morally and publicly unacceptable stratification of the community into "haves" and "have-nots," and the punishment of people for characteristics over which they have no control in violation of cherished beliefs in justice and equality. ${ }^{.}$The proper response to discrimination is legal prohibition.

On the other hand, the term discrimination may be used as an all-purpose descriptor for the practice of making distinc-

\footnotetext{
The information in this article is provided as an educational resource for geneticists to make them aware of relevant new developments in the law. It is not intended as, and should not be considered, legal advice. Adherence to any information or suggestions contained in the article is strictly voluntary and does not ensure compliance with legal requirements, and the authors of the article and the editors and publishers of Genetics in Medicine expressly disclaim any responsibility or liability therefor. If you have specific questions regarding the information discussed in the article, please seek the advice of your legal counsel.

From the School of Medicine, University of Louisville, Louisville, Kentucky.

Mark A. Rothstein, JD, School of Medicine, University of Louisville, Louisville, KY 40202.
}

tions. Further, some individuals and entities link social unacceptability with irrationality, that is, they believe that only irrational distinctions should be socially unacceptable. We refer to this as the actuarial definition. For example, in the insurance industry, the term discrimination is considered neutral and simply refers to classification for purposes of underwriting. On the industry view, discrimination only becomes problematic where there is no sound actuarial basis for the manner in which risks are classified, or individuals with equivalent risks are treated differently. ${ }^{6}$ Often, in the business context, "irrational" means that the distinction cannot be defended in economic terms or, in the case of insurance, by reference to sound actuarial principles.

For both definitions, the term genetic discrimination also conveys that adverse treatment is based solely on the genotype of asymptomatic individuals. Differential treatment on the basis of phenotype is frequently rational and accepted as a social necessity, such as where an employer bases a hiring decision on a job-related need for visual acuity. Cases of adverse treatment based on the phenotypic expression of a genetic characteristic fit well within the analytical framework of laws dealing with disability-based or health status-based discrimination generally. The most important of these laws is the Americans with Disabilities Act. ${ }^{7}$ To the contrary, cases of adverse treatment of phenotypically "normal" individuals fit poorly within the disability discrimination framework. A large majority of the public considers discrimination against these individuals as unfair because current opportunities are being denied to seemingly unaffected individuals merely because a genetic test or assessment indicates an increased risk of future incapacity.

We define discrimination as drawing a distinction among individuals or groups plus an element of either irrationality or social unacceptability or both. Our definition draws upon elements of both the civil rights and actuarial definitions. When discrimination is defined in this way, the term clearly has a negative connotation; discrimination is a bad thing. Even so, legal proscription of the classification may not be warranted. The appropriate legal and policy response to social unacceptability-a widely shared sense within a polity that some activity or state of affairs is "wrong"-will depend on the circumstances. In addition to or in lieu of legal prohibitions backed by criminal, civil, or administrative penalties are withdrawals of public funding, public condemnation, professional standards, and direct citizen action against the offending parties, for example, in the form of an economic boycott. Our definition recognizes that some forms of irrational discrimination are 
accepted, or at least tolerated, by society and some forms of discrimination are socially unacceptable, despite the fact that they are rational.

Table 1 illustrates the application of our definition of discrimination by indicating how a sample of selection criteria for employment would be arrayed along dimensions of social acceptability and rationality. Note that standards for judging social acceptability will vary according to the context. While employers are generally not prohibited from basing hiring decisions on Zodiac signs, even though this is clearly irrational, an insurer would have to offer some actuarial basis for the distinction in order to meet the requirements of state insurance laws. One justification for differences in the law of employment and insurance is that, in our society, there is no history of systematic mistreatment of Virgos relative to Capricorns in employment, and the costs of policing idiosyncratic factors in isolated hiring decisions would be very high. On the other hand, risk classification in insurance involves assigning individuals to risk pools; hence, insurance practices have the potential to create systematic mistreatment. Insurance underwriting policies also are more amenable to regulation than hiring decisions.

Historically, in insurance underwriting the law has mirrored the industry view that rational distinctions are acceptable. More recently, however, at least with respect to health insurance, this view is changing. In the United States, state laws prohibiting health insurers from gaining access to or using genetic information, and provisions of the Health Insurance Portability and Accountability Act (HIPAA) prohibiting employer-sponsored group health plans from using genetic information and other health-status related factors in underwriting, mark a significant expansion of the category of "rational but unacceptable."

Table 1

Categories of discrimination

\begin{tabular}{llc}
\hline & \multicolumn{1}{c}{ Rational } & \multicolumn{1}{c}{ Irrational } \\
\hline Acceptable & $\begin{array}{l}\text { Choosing an employee } \\
\text { based on relative skill } \\
\text { or other job-related } \\
\text { criteria }\end{array}$ & $\begin{array}{c}\text { - Choosing an employee } \\
\text { based on Zodiac sign }\end{array}$ \\
& & \\
& $\begin{array}{l}\text { Choosing an employee } \\
\text { based on medical } \\
\text { assessment of ability to } \\
\text { perform the job }\end{array}$ & $\begin{array}{l}\text { Choosing an employee } \\
\text { based on a coin toss }\end{array}$ \\
&
\end{tabular}

Unacceptable

$\begin{array}{ll}\begin{array}{l}\text { - Excluding a person } \\ \text { with cancer from } \\ \text { consideration for } \\ \text { employment based on } \\ \text { concerns about health } \\ \text { care costs }\end{array} & \begin{array}{l}\text { Excluding a person } \\ \text { from consideration for } \\ \text { employment based on } \\ \text { religion (in a secular } \\ \text { enterprise) }\end{array} \\ \text { - Excluding a pregnant } & \text { - Excluding a person } \\ \text { woman from } & \text { from consideration for } \\ \text { consideration for } & \text { employment based on } \\ \text { employment because } & \text { national origin } \\ \text { she may soon go on } & \\ \text { maternity leave } & \end{array}$

flects consensus about the importance of access to health care. Proposals to restrict or eliminate genetic discrimination in other insurance products do not yet enjoy the same degree of support. ${ }^{9}$ In countries that have universal access to health care, life insurance is now at the center of debate. ${ }^{10,11}$

\section{Why is it important to prevent (genetic) discrimination from the standpoint of ethics and policy?}

We have offered a definition of discrimination and described some of the points of controversy. Now, we ask why it is important, in certain contexts, to place discrimination based on genetic characteristics in the bottom two quadrants of Table 1 , that is, the reasons for labeling some uses of genetic information as rational but unacceptable or both irrational and unacceptable. Although there are many approaches to ethics and policy, broad agreement exists on a number of basic principles. These basic principles include respect for autonomy, justice, and beneficence. ${ }^{12,13}$

\section{Autonomy}

Autonomy refers to individual self-governance and includes the notion of respect for privacy. Autonomy is linked to the "idea of having a domain or territory of sovereignty for the self and a right to protect it." 13 Privacy is an umbrella term that encompasses an assortment of rights, including the right to limit access to one's person (e.g., to be free of bodily incursions, to refuse to provide information), the right to be left alone, and the right to keep information that has been conveyed to another person from disclosure to a third party. How might the use of genetic information to discriminate among individuals or groups undermine autonomy? If third parties demand genetic testing or access to genetic information as a condition to the receipt of essential goods, such as a job or health care, individuals effectively lose control over access to their bodies (e.g., for blood tests). More importantly, they lose control over the generation and dissemination of personal information and its subsequent use to control them.

Of course, control is eroded every time an insurer demands a cholesterol test. Although some assert otherwise, ${ }^{14-16}$ it is difficult to argue that genetic tests vary from cholesterol tests in kind. ${ }^{17}$ Genetic tests are, however, at the far end of the spectrum of medical tests in terms of the sensitiveness of the data, their potential for misinterpretation, and their relevance to family members. An insurer that requires a young woman with a family history of Huntington disease to undergo genetic testing effectively requires her to know, many years in advance, that she will (in all likelihood) die at an early age of a terrible disease or that she has escaped that fate, a fact that may drive a wedge between her and other family members. An employer that screens its employees for BRCA1/2 mutations generates information that may have significant implications for the children of the employees. Beyond this, so long as classification on the basis of genetic information is permitted, the person who tests positive for a $B R C A 1 / 2$ or Huntington disease mutation will find that his or her "domain of sovereignty" and range 
of opportunities have been sharply restricted. If some longestablished practices encourage or tolerate coercive predictive medical testing, then it is time to revisit the acceptability of those practices.

\section{Justice}

There is wide agreement that justice requires that "like cases be treated alike." However, this is a formal principle and leaves much to be determined. In discussions of discrimination in insurance based on genetic information, disagreement, and frequently, mutual incomprehension, mark exchanges between those committed to actuarial fairness and those committed to the view of fairness most closely associated with the philosopher John Rawls, who argued for "fair equality of opportunity" and for designing social institutions so that any inequalities work to the benefit of the least advantaged members of society. ${ }^{18}$

It has been common practice for insurers to engage in risk classification, looking at characteristics such as age, individual and family health history, health status, occupation, serum cholesterol, and alcohol and tobacco use. Insurers view genetic information as simply "one additional factor" to be evaluated in the underwriting process. ${ }^{6}$ For insurers, the key ethical consideration is a principle that might be stated as "groups with equal morbidity and mortality risk should be treated equally." This principle supports the use of any means that will increase precision in classification. At the same time, it can be used against underwriting practices that are subjective, arbitrary, or unsupported by evidence. Many questions remain about the value of the results of currently available predictive genetic tests in underwriting. ${ }^{19}$

Appeals to fairness to support a right of insurers to require genetic testing or gain access to results are frequently combined with expressions of concern about the financial viability of the insurance industry. Some argue that denying insurers access to information encourages moral hazard and adverse selection..$^{20}$ Moral hazard refers to the lessening of incentives to exercise care due to insurance. The concept has the most relevance to property insurance; logically, the effect will be weaker with goods, such as health or life, that are not easily replaced. Adverse selection refers to the disproportionately heavy purchase of insurance by high risk individuals when rates are not adjusted for risk. Insurers assume that individuals who learn that they are at high risk for disease, disability, and/or early death through confidential genetic testing will "load up" on insurance. Concerns about adverse selection are greatest in relation to life insurance, because there is no natural limit on payouts, and because the product is regarded as more discretionary than health insurance. Hence, it is significant that a recent study found little evidence that confidentiality protections for predictive genetic testing lead to adverse selection in life insurance..$^{21}$ One logical policy response to legitimate, if unsubstantiated, fears of exploitation would be a cap on the amount of life insurance that can be purchased without medical underwriting.
The burden of administration is another important economic consideration. Insurers already cover many people who have genetic disorders or predispositions to disease. ${ }^{19}$ If a result of the drive for greater precision in underwriting is to increase premiums for some existing insureds and decrease premiums for other existing insureds for policies of similar amounts, it is difficult to justify the administrative costs associated with genetic underwriting. The analysis will vary by type of insurance. ${ }^{22}$

The Rawlsian approach to justice begins, not with custom or economics, but with the idea of a level playing field and a belief that society should not allow people's prospects to be governed by "morally arbitrary" differences such as genetic factors related to disease and disability. ${ }^{23,24}$ On this view, broader social goals and an individual's degree of control over the characteristic that serves as the basis for discrimination matter in ethical and policy analysis. No contemporary, developed society operates on the principle that all individual differences can be a moral basis for advantage or disadvantage. In the United States, we generally disallow the use of race as a basis for decision making in employment, insurance, and other areas, without regard to rationality (e.g., relationship to life expectancy). On the other hand, we allow individuals to capitalize on educational attainment in the employment arena and to suffer penalties for tobacco use in the area of insurance.

Most work on genetics and justice has focused on health insurance, because health has a strong relationship to equality of opportunity, and because there is something troubling about making health insurance inaccessible when it is most needed. The big questions down the road will be whether restrictions on the use of predictive information should be strengthened and extended beyond the health insurance context, and whether identification of genetic correlates of behavior such as smoking will result in a re-drawing of the line between acceptable and unacceptable bases of classification. At present, there is little evidence that the use of predictive genetic information in insurance underwriting, especially as to complex disorders, can meet either the standards of Rawlsian fairness or actuarial fairness.

\section{Beneficence}

Beneficence has been described as the "obligation to help others further their important and legitimate interests." ${ }^{13}$ In policy making, beneficence requires consideration of the consequences of social practices. What are the consequences of allowing employers and insurers to obtain and use genetic information? Nearly two-thirds of respondents in a 1997 survey reported that they would not undergo genetic testing if employers and health insurers would have access to the results, and a 1995 Harris poll found that over $85 \%$ of respondents were very or somewhat concerned about access to and use of genetic information by employers and insurers. ${ }^{25}$ These data suggest that, absent legal protections against genetic discrimination, many individuals will refuse testing and will fail to take advantage of available interventions that might lower the morbidity and mortality associated with genetic disorders. Individuals may also decline to participate in research that might re- 
sult in advances in the treatment of genetic conditions if they cannot be assured of confidentiality. The individual and public health costs are likely to be enormous.

To date, the evidence of genetic discrimination has been anecdotal 26,27 or derived from studies with methodological weaknesses such as reliance on self-report. ${ }^{28}$ Hence, a recent study combining in-person interviews with health insurers and a direct market test has attracted considerable attention..$^{29}$ To the surprise of some, the investigators found that a person with a serious genetic condition but asymptomatic for disease would have little or no difficulty obtaining individual health insurance under current market conditions. They also concluded that there was no significant association between the degree of difficulty in obtaining insurance and the existence or absence of a state law regulating the use of genetic information. While these data may reassure patients worried about losing their health insurance, particularly if they are considering testing for the $B R C A 1$ or $B R C A 2$ mutations, other risks are not addressed, such as the risk of discrimination in life insurance or employment. Further, the finding that there is no widespread genetic discrimination in health insurance at present does not necessarily undermine the case for regulation. In the interviews, a general sense of legal and social disapproval emerged as an important consideration in insurers' decisions not to inquire about or require genetic testing.

\section{Why a focus on "genetic" discrimination is not workable}

There are good ethical reasons for preventing genetic discrimination. On the other hand, considerations of justice weigh against treating genetic discrimination differently from other forms of health status-based discrimination. There are also many practical considerations that weigh against separate treatment of genetic information. Three have become increasingly obvious over time: (1) We can't define "genetic"; (2) Even if we could define genetic, it is not feasible to separate genetic information from other health information; (3) Separate treatment increases the stigma attached to genetic conditions and lends legitimacy to genetic reductionism and determinism.

\section{We can't define genetic}

Discussions of genetic discrimination often note the linedrawing problems associated with the word "genetic." Is a family medical history "genetic" information? Is breast cancer a "genetic" disease? Is a sweat chloride test for cystic fibrosis a "genetic" test? A great deal of information concerning inherited genetic disorders can be derived from family history. Yet, state laws may define genetic information as including only information derived from laboratory tests. Narrow definitions also fail to protect information about genetic services, for example, whether an individual has ever undergone genetic testing or has participated in genetic research.

Monogenic disorders, in which the condition is caused by a single gene, are certainly genetic conditions. However, it is less clear that diagnostic tests analyzing proteins and other gene products are genetic tests under laws that apply to "direct" tests for abnormalities, defects, or deficiencies in genetic material, and expressly exclude tests for indirect manifestations of genetic disorders (e.g., Colorado, Indiana, Kansas, Ohio). Problems of definition will be exacerbated as genetic research turns increasingly to complex disorders. Scientists can be expected to identify a genetic component of numerous health problems. Researchers have already discovered a genetic contribution to some forms of diabetes, hypertension, hypercholesterolemia, epilepsy, osteoporosis, and various cancers. Because these and similar complex or multifactorial disorders are likely to be the main focus of future genetic inquiries in clinical and other settings, a DNA-based definition of "genetic" would be demonstrably underinclusive. Yet a more comprehensive definition would include virtually all medical conditions.

Even if we could define genetic, it is not feasible to separate genetic information from other health information

In most medical records, information about family history and similar matters is interspersed with other kinds of information. Editing or otherwise expunging genetic information from the patient's medical record before releasing it to authorized third parties would be burdensome and impractical. (By comparison, the results of HIV testing are fairly easy to isolate in the medical record.) Attempting to isolate genetic information so that, for example, only nongenetic information is maintained in patient records, might also compromise the quality of patient care, by impeding the access of health care professionals to this clinically significant information. Third parties such as employers and insurers will not be the only ones affected.

Separate treatment increases the stigma attached to genetic conditions and lends legitimacy to genetic reductionism and determinism

Separate treatment increases the stigma of genetic conditions. People may believe that because genetic conditions are singled out for protection, they must be particularly shameful. Separate treatment also encourages genetic reductionism, whereby all traits, health problems, and behaviors are attributed to genes, without regard to other factors. Genetic determinism is the belief that an individual's future "is defined and predicted by genetic make up and cannot be changed." ${ }^{30}$ Separate treatment suggests that genetic information is wholly unlike other kinds of health information and that genetic conditions are wholly unlike other kinds of health conditions.

\section{Why lawmakers nevertheless focus on "genetic" discrimination}

Although a focus on genetic discrimination is not workable, U.S. lawmakers continue to introduce, and frequently pass, bills that single out genetic information for special protections. A number of explanations can be offered for this behavior. The first is ignorance. Some lawmakers may simply fail to grasp the practical problems reviewed in the preceding section. Another factor may be the lobbying efforts of genetic advocacy groups. Many are highly effective in representing their constituencies. Yet, it is not clear whether the strategy of promoting "genetic" legislation is 
efficacious, tactically sound, or ethical when these laws have so little value to those at risk of genetic disorders (because they protect only asymptomatic individuals) and no value to those who have illnesses from other causes. The most important factor behind the focus on genetic discrimination may be political reality. Efforts to pass more comprehensive legislation protecting the privacy of health information and eliminating the potential for discrimination on the basis of health information, through universal coverage, have failed—so far. Although genetic discrimination may be a more manageable target, enactment of such legislation may give the misleading impression that the issue of health discrimination has been addressed, thereby further delaying enactment of more meaningful reforms.

\section{Conclusion: Why the problem is not amenable to a quick fix or single statutory measure}

The potential for genetic discrimination extends to every social domain. This includes commercial transactions where one party has an economic interest in the future health of the other party (e.g., mortgages, commercial loans). It also includes the diverse noneconomic area, where there is interest in explaining or predicting an individual's current or future health (e.g., child custody, personal injury law) or behavior (e.g., schools, criminal law). ${ }^{31}$

Any effort to address genetic discrimination inevitably implicates broader and extremely contentious issues, such as the right to health care. ${ }^{32}$ If we wish to eliminate genetic discrimination in health insurance without creating questionable distinctions between genetic and other conditions, and without risking system collapse through adverse selection, we need to work toward mandatory participation, guaranteed issue and renewal, community-rated health insurance. If we wish to eliminate genetic discrimination in employment, without endorsing questionable distinctions, and without risking a system in which protections against discrimination are vitiated by ease of access to information and the difficulties involved in policing its use, we need to prohibit employers from obtaining all non-job-related medical information.

Short of these kinds of fundamental reforms, there are some incremental reforms that will partially address the problem of genetic discrimination. Relying on the preceding discussion, we propose three policy guides. First, it is appropriate and necessary to use law and other means of implementing public policy to end irrational discrimination, except where its effects are trivial (the hiring-by-Zodiac case) and the costs of regulation are high. Second, commitments to autonomy, justice, and beneficence may justify regulation of discrimination even where it is in some sense rational. Third, generic approaches are preferable to genetic ones.

Limited measures are not valueless. Still, given the pace of progress in the field of genetics and the likely ubiquitous nature of genetic information in medical records and elsewhere, we will soon reach a point where we will be forced to address the more fundamental issues.

\section{References}

1. Kinsley M. We must gather courage to discriminate genetically. Houston Chronicle, April 23, 2000, 4C.

2. Sullivan A. Promotion of the fittest. NY Times Mag, July 23, 2000, 16.

3. Collins FS. Medical and societal consequences of the human genome project. NEngl J Med 1999;341:28-37.

4. Girion L. Nurse derails genetic testing. LA Times, Feb. 25, 2001, W1.

5. Council for Responsible Genetics. Position paper on genetic discrimination, 2001, www.gene-watch.org/programs/GD_PP.html.

6. Pokorski RJ. Use of genetic information by private insurers. In: Murphy TF, Lapp MA, editors. Justice and the human genome project. Berkeley: University of California Press, 1994:91-109.

7. Americans with Disabilities Act. 42 U.S.C. Sec. 12101-12213, 1990.

8. Health Insurance Portability, and Accountability Act. 42 U.S.C. Sec. 300gg-300gg-2, 1996.

9. Rothstein MA. Predictive genetic testing for Alzheimer's disease in long-term care insurance. Ga L Rev 2001;35:707-733.

10. Hinsliff G. Genetic tests clampdown. The Observer, April 15, 2001, www.observer.co.uk.

11. Altman D. Genetics and insurance. Prospect, April 2001, www.prospect-magazine.co.uk.

12. National Commission for the Protection of Human Subjects of Biomedical and Behavioral Research. The Belmont report: ethical principles and guidelines in the conduct of research involving human subjects. Washington, D.C.: Department of Health, Education, and Welfare, 1979.

13. Beauchamp TL, Childress JF. Principles of biomedical ethics, 5th Ed. New York: Oxford University Press, 2001.

14. Annas GJ. Genetic privacy: there ought to be a law. Tex Rev L \& Pol 1999;4:9-15.

15. Annas GJ, Glantz LH, Roche PA. Drafting the Genetic Privacy Act: science, policy, and practical considerations. J Law Med Ethics 1995;23:360-366.

16. Annas GJ. Privacy rules for DNA databanks: Protecting coded "future diaries." JAMA 1993;270:2346-50.

17. Murray T. Genetic exceptionalism and "future diaries." In: Rothstein MA, editor. Genetic secrets: protecting privacy and confidentiality in the genetic era. New Haven: Yale University Press, 1997:60-73.

18. Rawls J. A theory of justice. Cambridge: Harvard University Press, 1971.

19. Lowden AJ. The current state of genetic testing in life insurance. In: Genetic testing: implications for insurance (Symposium Proceedings). Schaumburg, IL: Actuarial Foundation, 1998.

20. Brockett PL, Tankersley SE. The genetics revolution, economics, ethics and insurance. J Bus Ethics 1997;16:1661-1676.

21. Zick CD, Smith KR, Mayer RN, Botkin JR. Genetic testing, adverse selection, and the demand for life insurance. Am J Med Genet 2000;93:29-39.

22. Rothstein MA. Genetics, insurance, and the ethics of genetic counseling. In: Friedmann T, editor. Molecular genetic medicine, Vol. 3. San Diego: Academic Press, 1993:159-177.

23. Daniels N. The human genome project, individual differences, and just health care. In: Murphy TF, Lapp MA, editors. Justice and the human genome project. Berkeley: University of California Press, 1994:110-111.

24. Buchanan A, Brock DW, Daniels N, Wikler D. From chance to choice: genetics and justice. New York: Cambridge University Press, 2000.

25. U.S. Department of Labor, Department of Health and Human Services, Equal Employment Opportunity Commission, and Department of Justice. Genetic information and the workplace. Washington, DC: U.S. Department of Labor, 1998: 2 (citing National Center for Genome Resources unpublished survey, 1997, and Harris Poll no. 34, 1995).

26. Billings PR, Kohn MA, deCuevas M, Beckwith J, Alper JS, Natowicz M. Discrimination as a consequence of genetic testing. Am J Hum Genet 1992;50:476-482.

27. Geller LN, Alpers JS, Billings PR, Barash CI, Beckwith J, Natowicz N. Individual, family, and societal dimensions of genetic discrimination: a case study analysis. $\mathrm{Sci}$ Eng Ethics 1996;2:71-88.

28. Lapham EV, Kozma C, Weiss JO. Genetic discrimination: perspectives of consumers. Science 1996;274:621-624.

29. Hall MA, Rich SS. Laws restricting health insurers' use of genetic information: impact on genetic discrimination. Am J Hum Genet 2000;66:293-307.

30. Rothenberg KH. Breast cancer, the genetic "quick fix," and the Jewish community. Health Matrix 1997;7:97-124.

31. Rothstein MA. Genetic secrets: a policy framework. In: Rothstein MA, editor. Genetic secrets: protecting privacy and confidentiality in the genetic era. New Haven: Yale University Press, 1997:451-495.

32. Rothstein MA. Genetic privacy and confidentiality: why they are so hard to protect. J Law Med Ethics 1998;26:198-204. 